\title{
Splanchnic Block for Back Pain - A Unique Case
}

\section{Prakash Deshmukh ${ }^{1}$, Helee Thakar ${ }^{2 *}$, Manjiri Ranade $^{3}$ and Kailash Kothari $^{4}$}

${ }^{1}$ FIPP (Fellow of International Pain Physicians), FIAPM (Fellow of Indian Academy of Pain Medicine), D. Anaesthesiology, Spine and Pain Management Centre, Kalyan West Pain Clinic of India, Mumbai, Maharashtra, India

${ }^{2}$ Fellow, MD Anaesthesiology, Pain Clinic of India, Chembur, Mumbai, Maharashtra, India

${ }^{3}$ FAIPM, D. Anaesthesiology, Pain Clinic of India, Thane, Mumbai, Maharashtra, India

${ }^{4}$ FIAPM, MD Anaesthesiology, Director, Pain Clinic of India, Chembur, Mumbai,

Maharashtra, India

*Corresponding Author: Helee Thakar, Fellow, MD Anaesthesiology, Pain Clinic of India, Chembur, Mumbai, Maharashtra, India.
Received: September 01, 2021

Published: November 25, 2021

(C) All rights are reserved by Helee Thakar., et al.

\section{Abstract}

The thoracic splanchnic nerves supply vasomotor and sensory fibres to various abdominal organs, notably the stomach and duodenum. Any pathology that affects these organs relays sensation via these nerves, and frequently presents as intra-abdominal pain or discomfort. Although this pain may radiate to the back, isolated back pain of a neuropathic nature is rare. We present a case that showed a unique presentation of neuropathic back pain following peptic ulcer disease, who was treated with splanchnic block.

Keywords: Splanchnic Nerves; Peptic Ulcer Disease; Back Pain; Neuropathy; Celiac Plexus

\section{Introduction}

The sympathetic autonomic nervous system has a thoracolumbar outflow. Of the various nerves that exit the sympathetic chain, the thoracic splanchnic nerves supply the abdominal viscera and receive afferents from intra-abdominal organs. The thoracic splanchnic nerves are divided into the greater splanchnic nerve (T5-T10), the lesser splanchnic nerve (T10-T11) and the least splanchnic nerve (T12) [1,2].

Generally, when one of these nerves is affected, the patient complains of upper abdominal pain usually in the epigastrium or hypochondrium which may refer to the back $[1,3]$. Isolated back pain of a burning nature is rare for intra-abdominal pathology.

Radiofrequency ablation of the splanchnic plexus and celiac plexus have been used to treat intra-abdominal pain in patients of various abdominal pathologies such as tumours, gastro-esophageal reflux disease (GERD), chronic duodenal ulcer, etc. However, the efficacy of splanchnic plexus block has been proved to be higher than celiac plexus block in patients with chronic abdominal pain due to non-malignant causes [3].

\section{Case Report}

A 44-year old female presented to us with complaints of burning pain in her back, extending from lower thoracic to the lumbar region in the mid-scapular line on the right side for 3-4 months. She was relatively asymptomatic 4 months back, when she developed abdominal pain that lasted for 1 month and was treated for peptic ulcer disease. She started experiencing burning pain in her back extending from the 10th rib to the upper sacral region on the right for 3 months and consulted different doctors (including physician, 
orthopaedic surgeon and neurologist) who gave various medicines but were unable to treat the pain. She was then referred to our centre.

Since the past two weeks, the pain had been radiating to her right lower limb and right shoulder. Occasionally, the pain would radiate to her right upper arm. The pain was burning in nature, continuous, not aggravated or relieved by any factor and was not associated with numbness, tingling, loss of sensation or motor deficit. The pain interfered with her ability to perform daily activities, and she experienced difficulties in reclining, lying down and sleeping. She had not undergone any procedure or intervention for this pain.

She did not have a history of any other disease.

Our senior pain physician diagnosed her as having post peptic ulcer neuropathy involving the splanchnic nerves. She was treated with a right-sided splanchnic block under fluoroscopy guidance at T10 level using local anaesthesia $(0.5 \%$ Bupivacaine $3 \mathrm{~mL})$ and steroid (Triamcinolone $40 \mathrm{mg}$ ) combination. The patient experienced immediate relief in her symptoms and reported a 100\% relief from pain after 24 hours.

\section{Discussion}

The thoracic splanchnic nerves arise from the sympathetic chain bilaterally along the T5-T12 vertebra. They are divided according to the level at which they arise, into the greater, lesser and least splanchnic nerves [1,2].

\begin{tabular}{|l|c|c|c|}
\hline & $\begin{array}{c}\text { Greater } \\
\text { Splanchnic } \\
\text { Nerve }\end{array}$ & $\begin{array}{c}\text { Lesser } \\
\text { Splanchnic } \\
\text { Nerve }\end{array}$ & $\begin{array}{c}\text { Least } \\
\text { Splanchnic } \\
\text { Nerve }\end{array}$ \\
\hline Origin & T5-T10 & T10-T11 & T12 \\
\hline Supplying to & $\begin{array}{c}\text { Celiac gan- } \\
\text { glia }\end{array}$ & $\begin{array}{c}\text { Superior mesen- } \\
\text { teric/Aorticore- } \\
\text { nal ganglia }\end{array}$ & Renal Plexus \\
\hline
\end{tabular}

Table 1

These nerves carry vasomotor fibres and sensory fibres from the viscera [4]. The stomach and proximal duodenum are supplied by the celiac and superior mesenteric ganglia. Any pathology of the stomach or the first part of the duodenum will produce pain and abnormal sensation that are carried through the thoracic splanchnic nerves. This pain is usually experienced as intra-abdominal pain and discomfort but may be referred to the back $[1,3]$.

Our patient had a history of peptic ulcer disease and had experienced abdominal pain which was followed by back pain of a burning nature. We therefore chose to target the sympathetic chain at T10 level as it would be easier to cover both the greater and lesser splanchnic nerves with a single injection.

It has been found that celiac plexus blocks are effective in controlling abdominal pain due to intra-abdominal pathologies. However, recent data shows that splanchnic plexus blocks are better as they have an easier needle placement and lesser complications when compared to celiac plexus blocks [3]. Also, splanchnic blocks have been shown to be more effective in terms of efficacy and longevity for pain relief compared to celiac plexus blocks in patients with non-malignant intra-abdominal pain [4]. Thus, we chose to perform a splanchnic block instead of celiac plexus block in this patient.

Pre-procedure, the patient used to have continuous burning pain that affected her daily routine and sleep. She was unable to lean back or sleep in a reclining position comfortably. Immediately after the procedure, she experienced a decrease in pain, on-table and was satisfied with the result. This indicated that the procedure was successful.

\section{Conclusion}

It is vital to rule out intra-abdominal pathology as a cause of atypical back pain through the patient's history and investigations. The presentation of pain in such cases may vary. One must consider splanchnic nerve block for pain relief in such unique cases.

\section{Conflict of Interest}

The authors declare that there is no conflict of interest.

\section{Bibliography}

1. Loukas M., et al. "A review of the thoracic splanchnic nerves and celiac ganglia". Clinical Anatomy 23.5 (2010): 512-522.

2. Yang H-J., et al. "Anatomy of thoracic splanchnic nerves for surgical resection". Clinical Anatomy 21.2 (2008): 171-177. 
3. Kapural L., et al. "Splanchnic block at T11 provides a longer relief than celiac plexus block from nonmalignant, chronic abdominal pain". Pain Management 9.2 (2019): 115-121.

4. AL-Jumah R., et al. "Radiofrequency Ablation and Alcohol Neurolysis of the Splanchnic Nerves for a Patient With Abdominal Pain From Pancreatic Cancer". Cureus 12.10 (2020): e10758.

Volume 4 Issue 12 December 2021

(C) All rights are reserved by Helee Thakar., et al. 